\title{
Role of CA-EDTA on the Synthesizing Process of Cerate-Zirconate Ceramics Electrolyte
}

\author{
Nur Athirah Abdullah, Sharizal Hasan, and Nafisah Osman \\ Faculty of Applied Sciences, Universiti Teknologi MARA, Perlis, 02600 Arau, Malaysia \\ Correspondence should be addressed to Nafisah Osman; fisha@perlis.uitm.edu.my
}

Received 24 May 2012; Accepted 23 September 2012

Academic Editor: Patricia Valentao

Copyright (c) 2013 Nur Athirah Abdullah et al. This is an open access article distributed under the Creative Commons Attribution License, which permits unrestricted use, distribution, and reproduction in any medium, provided the original work is properly cited.

The role of a combination between citric acid (CA) and ethylenediaminetetra acetic acid (EDTA) as chelating agents in preparation of $\mathrm{BaCe}_{0.54} \mathrm{Zr}_{0.36} \mathrm{Y}_{0.1} \mathrm{O}_{2.95}$ powder by a modified sol-gel method is reported. The precursor solutions were prepared from metal nitrate salts $\left(\mathrm{M}^{+}\right)$, chelating agents $(\mathrm{C})$, and ethylene glycol (EG) at molar ratio of $\mathrm{M}^{+}: \mathrm{C}: \mathrm{EG}=3: 2: 3$. Chemical and phase transformation of samples during thermal decomposition were analyzed by thermogravimetric analysis (TGA) and Fourier transform infrared (FTIR) spectroscopy. TGA results show that the sample prepared by a combination of CA-EDTA exhibited the lowest thermal decomposition temperature, $T_{\text {td }}$ since there was no significant weight loss after $750^{\circ} \mathrm{C}$. After calcined at $1100^{\circ} \mathrm{C}$, the carbonates residue remained in the samples as proven by FTIR results. It was found that the used combination of CA-EDTA acts as a better combustion reagent to increase the reaction rate and influence the thermal decomposition behaviour compared to a single citric acid and EDTA, respectively. Apparently, calcination temperatures above $1100^{\circ} \mathrm{C}$ are needed to produce a pure perovskitic $\mathrm{BaCe}_{0.54} \mathrm{Zr}_{0.36} \mathrm{Y}_{0.1} \mathrm{O}_{2.95}$.

\section{Introduction}

Ceramics based on cerate-zirconate have been widely studied due to their potential as an electrolyte in electrochemical devices. This type of ceramics has a high protonic conductivity and a better chemical stability in $\mathrm{CO}_{2}$-containing atmosphere $[1,2]$. The conventional method used for the preparation of this ceramics powder is solid-state reaction (SSR) [3]. Nevertheless, synthesis through this route required heat treatment at high temperature and repetitive grinding, compaction, and annealing process. As a result, microhomogeneous phase structures are difficult to obtain, due to large and strongly bonded powder agglomeration $[4,5]$.

A promising approach to reduce the calcination temperatures is the use of a soft, wet chemical methods (WCMs), which have the advantage of producing finer powder morphologies [6-8]. In particular, a polymerized complex process such as a modified sol-gel method is an attractive method for preparing ultrafine oxide strength with a high phase purity. One possible route to lower the temperature processing in this method is by using different chelating agents. The differences in chelating power give different interactions in chelation process $[4,9,10]$.

Chelating agents such as citric acid and EDTA play an important role in synthesizing of ceramics powder. The combined citrate-EDTA method is particularly useful for synthesizing ultrafine powders of complex oxide compositions [11]. It also can eliminate the occurrence of unbound metal cations so as to ensure the complexation of all metal cations to give homogenous precursors. In addition, this combination is able to bind the metal cations in the precursor solution completely [12]. In this present work, $\mathrm{BaCe}_{0.54} \mathrm{Zr}_{0.36} \mathrm{Y}_{0.1} \mathrm{O}_{2.95}$ was prepared using citrate-EDTA complexing method. During this process, besides citrates as primary coordinate agent, a suitable amount of EDTA was used as a secondary coordinate agent, which has a comparatively stronger complexing ability. The cooperation of EDTA and citric acid may result in more stable chelate complex. This study focused on the thermal characteristic synthesis of the sample prepared with a single chelating agent and combinations of CA-EDTA. 


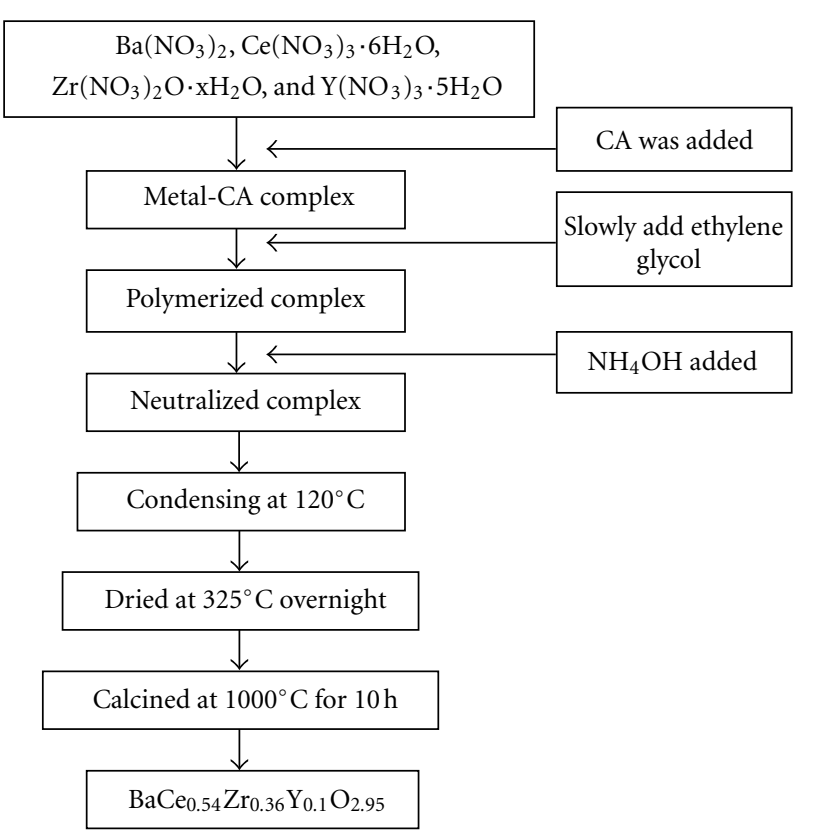

(a)

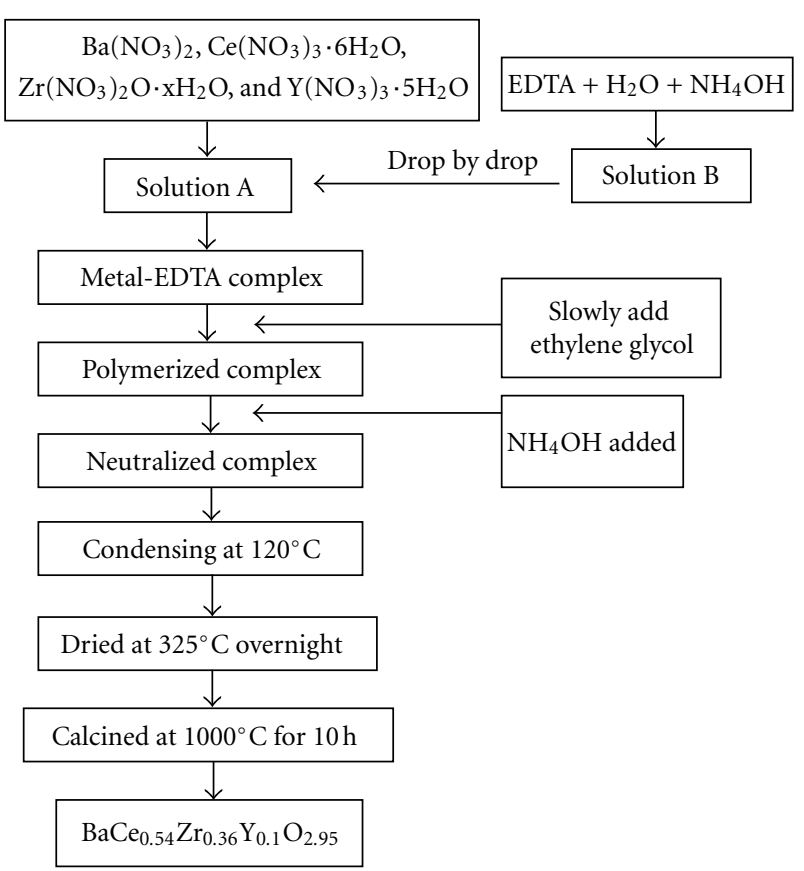

(b)

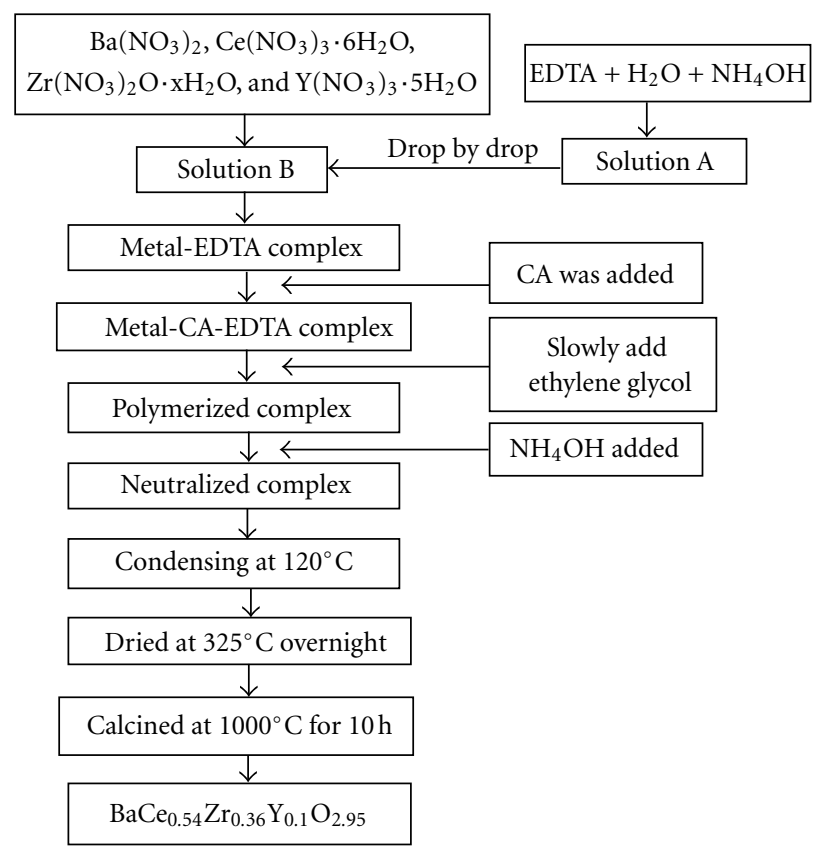

(c)

FIgURE 1: Synthesizing process of BCZY using (a) citric acid method, (b) EDTA method, (c) CA-EDTA method.

\section{Experimental}

2.1. Sample Preparation. Raw materials of $\mathrm{Ba}\left(\mathrm{NO}_{3}\right)_{2}$ (99\%, ACROS), $\mathrm{Ce}\left(\mathrm{NO}_{3}\right)_{3} \cdot 6 \mathrm{H}_{2} \mathrm{O}$ (99.5\%, ACROS), $\mathrm{Zr}\left(\mathrm{NO}_{3}\right)_{2} \mathrm{O} \cdot \mathrm{xH}_{2} \mathrm{O}$ (99.5\%, ACROS), and $\mathrm{Y}\left(\mathrm{NO}_{3}\right)_{3} \cdot 5 \mathrm{H}_{2} \mathrm{O}$ (99.9\%, Aldrich) were used to prepare $\mathrm{BaCe}_{0.54} \mathrm{Zr}_{0.36} \mathrm{Y}_{0.1} \mathrm{O}_{2.95}$ (denoted as BCZY). Citric acid monohydrate, CA (MERCK) and ethylenediaminetetraacetic acid, EDTA (99\%, ACROS) were chosen as chelating agents and ethylene glycol (99\%, ACROS) was used as polymerization agent.

Figures 1(a), 1(b), and 1(c) illustrate the flow chart of sample preparation process via three different routes named as CA method, EDTA method, and CA-EDTA method. For CA method, all the raw materials were dissolved in distilled water and continuously were stirred using a magnetic stirrer. Then the citric acid was gradually added into the metal nitrate 


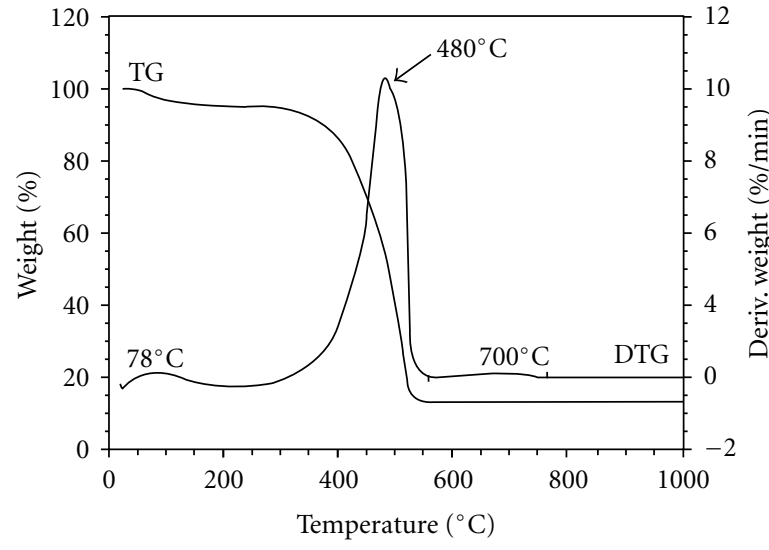

(a)

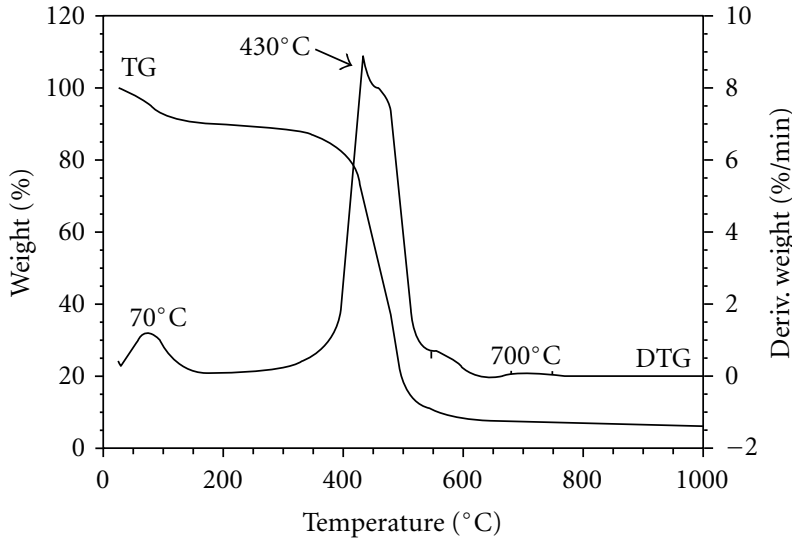

(b)

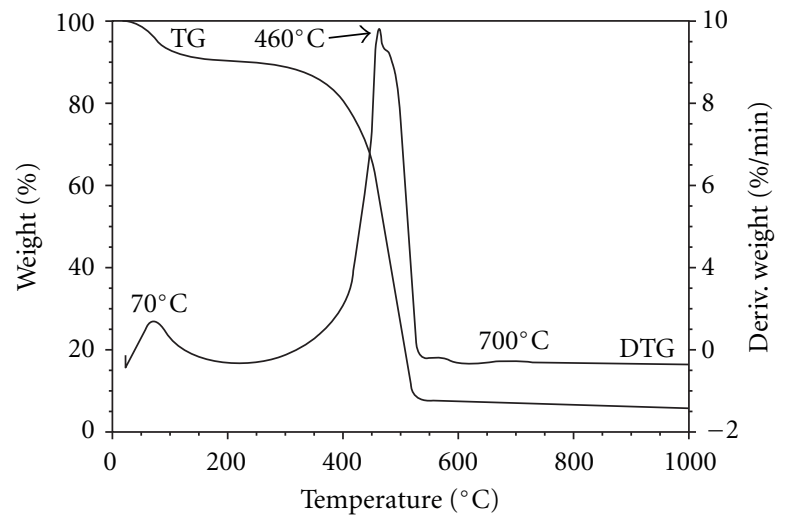

(c)

Figure 2: TG/DTG curve for (a) S1, (b) S2, and (c) S3 dried powder $\left(325^{\circ} \mathrm{C}\right.$ ).

solution to form metal-citric acid complexes. For EDTA method, a 25\% ammonia solution was added to EDTA until it was completely dissolved in deionised water at $\mathrm{pH} 6$ (solution A). The metal nitrate solution was separately dissolved in deionised water to form aqueous precursor solution (solution B). To this solution the $\mathrm{NH}_{4} \mathrm{OH}$-EDTA was added under continuous magnetic stirring and formed metal-EDTA complexes. The $\mathrm{pH}$ of the solution was maintained at 6. CAEDTA method is defined as the combination of CA method and EDTA method. $\mathrm{NH}_{4} \mathrm{OH}$ was added to promote the dissolution of EDTA in deionised water and form aqueous solution of EDTA. Then, this solution was added to the metalnitrate salt solution. Finally, an appropriate amount of citric acid was added (CA : EDTA : metal $=1: 1: 2$ ) to form metal CA-EDTA complexes. The resulting solution was denoted as S1, S2, and S3 for using CA, EDTA, and CA-EDTA as chelating agents, respectively.

Ethylene glycol then was added into the S1, S2, and S3 under continuous stirring. The concentrated ammonia solution was gradually added until the $\mathrm{pH}$ of S1, S2, S3 maintains at 6-7. The resulting solution was heated at $90^{\circ} \mathrm{C}$ and stirred continuously using a hot plate and a magnetic stirrer. The heating and stirring process was controlled accordingly. The solution then was further heated until a dark brown gel was obtained. The gel was dried on a hot plate overnight and then calcined at $325^{\circ} \mathrm{C}, 550^{\circ} \mathrm{C}$, and $1100^{\circ} \mathrm{C}$ with heating rate of $10^{\circ} \mathrm{C} \mathrm{m^{-1 }}$ for $10 \mathrm{~h}$ to produce light yellow powders.

2.2. Sample Characterization. The thermal behaviour of the obtained gels was characterized by a thermogravimetric analysis (TGA) model SDT Q600. Fifteen milligram of the dried powder $\left(325^{\circ} \mathrm{C}\right)$ was placed in a sample holder and heated from $25-1000^{\circ} \mathrm{C}$ under synthetic air (flow rate $100 \mathrm{~mL} / \mathrm{min}$ ) with heating rate $10^{\circ} \mathrm{C} / \mathrm{min}$, and weight change was recorded as a function of temperature. A Fourier transform infrared (FTIR) spectroscopy (model Nicolet 380) was used to study the molecular structure of the gels and the calcined powders in the frequency range $400-4000 \mathrm{~cm}^{-1}$ using $\mathrm{KBr}$ pellets.

\section{Results and Discussion}

3.1. Thermal Analysis. TG/DTG diagrams of BCZY prepared with three different chelating agents are shown in Figures 2(a), 2(b), and 2(c). The TG/DTG profile of all the precursors exhibits almost a similar decomposition behaviour. There are three stages of weight loss for all the samples. The first stage of weight loss from room temperature to $240^{\circ} \mathrm{C}$ as corroborated by an exothermic peaks (or hump) at $78^{\circ} \mathrm{C}$ for $\mathrm{S} 1$ and $70^{\circ} \mathrm{C}$ for S2 and S3 is corresponding to the vaporization of 
TABLE 1: Summarization of the thermal characteristics of the dried sample $\left(325^{\circ} \mathrm{C}\right)$.

\begin{tabular}{|c|c|c|c|c|c|}
\hline Sample & Stages & Temperature range $\left({ }^{\circ} \mathrm{C}\right)$ & DTG peak $\left({ }^{\circ} \mathrm{C}\right)$ & Mass loss (\%) & Heat released $(\mathrm{J} / \mathrm{g})$ \\
\hline \multirow{3}{*}{ S1 } & 1 & $27-240$ & 78 & 9 & \multirow{3}{*}{12573} \\
\hline & 2 & $240-590$ & 480 & 82 & \\
\hline & 3 & $590-800$ & 700 & 1 & \\
\hline \multirow{3}{*}{ S2 } & 1 & $27-240$ & 70 & 9 & \multirow{3}{*}{11276} \\
\hline & 2 & $240-610$ & 430 & 81 & \\
\hline & 3 & $610-770$ & 700 & 1 & \\
\hline \multirow{3}{*}{ S3 } & 1 & $27-240$ & 70 & 9 & \multirow{3}{*}{10795} \\
\hline & 2 & $240-610$ & 460 & 83 & \\
\hline & 3 & $610-750$ & 700 & 1 & \\
\hline
\end{tabular}

the absorbed water. A significant weight loss of all samples is in temperature range from $240-600^{\circ} \mathrm{C}$ (stage 2), due to the decomposition of the residual oxidizer (nitrates), amino group, and the organic substance. The burning of the redundant combustion agents result in the release of great amounts of $\mathrm{CO}_{2}, \mathrm{H}_{2} \mathrm{O}$, and $\mathrm{NO}_{2}$ gases. A possible reaction equation for this combustion process can be written as Reaction 1, Reaction 2, and Reaction 3.

Reaction 1: citric acid as chelating agent

$$
\begin{aligned}
\mathrm{Ba}\left(\mathrm{NO}_{3}\right)_{2}+0.1 \mathrm{Y}\left(\mathrm{NO}_{3}\right)_{3} \cdot 6 \mathrm{H}_{2} \mathrm{O}+0.54 \mathrm{Ce}\left(\mathrm{NO}_{3}\right)_{3} \cdot 6 \mathrm{H}_{2} \mathrm{O} \\
\quad+0.36 \mathrm{Zr}\left(\mathrm{NO}_{3}\right)_{2} \mathrm{O} \cdot 5 \mathrm{H}_{2} \mathrm{O}+\mathrm{C}_{6} \mathrm{H}_{8} \mathrm{O}_{7} \cdot \mathrm{H}_{2} \mathrm{O} \\
\quad+\mathrm{C}_{2} \mathrm{H}_{6} \mathrm{O}_{2}+2 \mathrm{NH}_{4} \mathrm{OH}+8.5 \mathrm{O}_{2} \\
\longrightarrow \mathrm{BaCe}_{0.54} \mathrm{Zr}_{0.36} \mathrm{Y}_{0.1} \mathrm{O}_{2.95}+8 \mathrm{CO}_{2}+13 \mathrm{H}_{2} \mathrm{O}+\mathrm{N}_{2}
\end{aligned}
$$

Reaction 2: EDTA as chelating agent

$$
\begin{aligned}
\mathrm{Ba}\left(\mathrm{NO}_{3}\right)_{2}+0.1 \mathrm{Y}\left(\mathrm{NO}_{3}\right)_{3} \cdot 6 \mathrm{H}_{2} \mathrm{O}+0.54 \mathrm{Ce}\left(\mathrm{NO}_{3}\right)_{3} \cdot 6 \mathrm{H}_{2} \mathrm{O} \\
\quad+0.36 \mathrm{Zr}\left(\mathrm{NO}_{3}\right)_{2} \mathrm{O} \cdot 5 \mathrm{H}_{2} \mathrm{O}+\mathrm{C}_{10} \mathrm{H}_{16} \mathrm{~N}_{2} \mathrm{O}_{8} \\
\quad+\mathrm{C}_{2} \mathrm{H}_{6} \mathrm{O}_{2}+4 \mathrm{NH}_{4} \mathrm{OH}+15.5 \mathrm{O}_{2} \\
\longrightarrow \mathrm{BaCe}_{0.54} \mathrm{Zr}_{0.36} \mathrm{Y}_{0.1} \mathrm{O}_{2.95}+12 \mathrm{CO}_{2}+21 \mathrm{H}_{2} \mathrm{O}+3 \mathrm{~N}_{2}
\end{aligned}
$$

Reaction 3: CA-EDTA as chelating agent

$$
\begin{aligned}
\mathrm{Ba}\left(\mathrm{NO}_{3}\right)_{2}+0.1 \mathrm{Y}\left(\mathrm{NO}_{3}\right)_{3} \cdot 6 \mathrm{H}_{2} \mathrm{O}+0.54 \mathrm{Ce}\left(\mathrm{NO}_{3}\right)_{3} \cdot 6 \mathrm{H}_{2} \mathrm{O} \\
\quad+0.36 \mathrm{Zr}\left(\mathrm{NO}_{3}\right)_{2} \mathrm{O} \cdot 5 \mathrm{H}_{2} \mathrm{O}+\mathrm{C}_{6} \mathrm{H}_{8} \mathrm{O}_{7} \cdot \mathrm{H}_{2} \mathrm{O} \\
\quad+\mathrm{C}_{10} \mathrm{H}_{16} \mathrm{~N}_{2} \mathrm{O}_{8}+\mathrm{C}_{2} \mathrm{H}_{6} \mathrm{O}_{2}+4 \mathrm{NH}_{4} \mathrm{OH}+31 \mathrm{O}_{2} \\
\longrightarrow \mathrm{BaCe}_{0.54} \mathrm{Zr}_{0.36} \mathrm{Y}_{0.1} \mathrm{O}_{2.95}+18 \mathrm{CO}_{2}+26 \mathrm{H}_{2} \mathrm{O}+3 \mathrm{~N}_{2}
\end{aligned}
$$

The actual reaction may not be exactly as proposed because $\mathrm{N}_{2}$ may be $\mathrm{NO}, \mathrm{NO}_{2}$, or other forms. After this reaction, the organics were eliminated from the gel and the metal oxide started to form as shown in the DTG curve. The DTG curve revealed a strong and sharp exothermic peak in the range of $430^{\circ} \mathrm{C}-480^{\circ} \mathrm{C}$ which was likely due to the oxidation or combustion of the chelate complex along with the forming of metal oxides. These were also reported by Tao et al. when using a combination CA-EDTA as chelating agents for synthesizing $\mathrm{La}_{0.6} \mathrm{Sr}_{0.4} \mathrm{CoO}_{3-\alpha}$ [11]. S3 showed higher weight loss compared to S1 and S2 since two combinations of organics compound (CA and EDTA) were used. As proposed in the Reaction 3, a combination of CA-EDTA released about $18 \mathrm{~mol}$ of the $\mathrm{CO}_{2}$ gaseous per reaction. Roy et al. reported that the higher ratio of the degree of the chelation process of the metal in the organic product will lead to an excess of organics. The last stage of thermal decomposition shows $1 \%$ weight loss with a minor exothermic peak at $\sim 700^{\circ} \mathrm{C}$ for all samples indicate that the elimination of the organics compound in the samples is almost completed.

Table 1 shows the summarization of the thermal decomposition characteristic and the value for heat released due to the combustion of the organic constituent in the gel precursors. The DSC curve is presented in Figures 3(a), 3(b), and 3(c) which have one or two exothermic peaks observed. The gel prepared with citric acid has the highest amount of heat released $(12573 \mathrm{~J} / \mathrm{g})$ during the burn-out of the organic compound that does not strongly chelate to the citric acid. This might be due to weak electron donating group in citric acid to chelate all metal cations. It is known that one metal ion can be chelated by three bonds to the one molecule of citric acid. On the other hand, one metal ion can be chelated by six bonds to one molecule of EDTA because it has 2 types of electron donating groups which are carboxylic and aliphatic amine. So, EDTA has a comparatively strong chelating power compared to citric acid $[13,14]$. The combination of CA and EDTA seems to accommodate the process of formation of perovskite. This combination increased the chelating power towards metal ions and reduced the processing temperature of the cerate-zirconate ceramics as proved by S3 that showed the lowest $T_{\text {td }}$ compared to $\mathrm{S} 1$ and S2. In addition, it also reduced the amount of heat released indicating the effectiveness of chelation process.

These DTG results can be further explained in terms of kinetic analysis. It is convenient to express a reaction by using a certain function $f(\alpha)$, of the reaction extent, $\alpha$. The degree of conversion $(\alpha)$ can be calculated using

$$
\alpha=\frac{\% m_{i}-\% m_{t}}{\% m_{i}-\% m_{f}}
$$




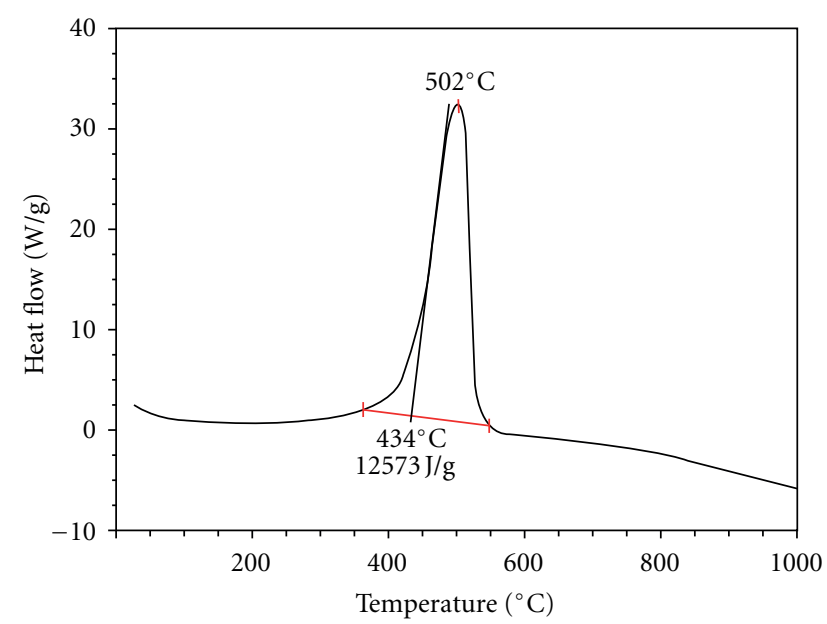

(a)

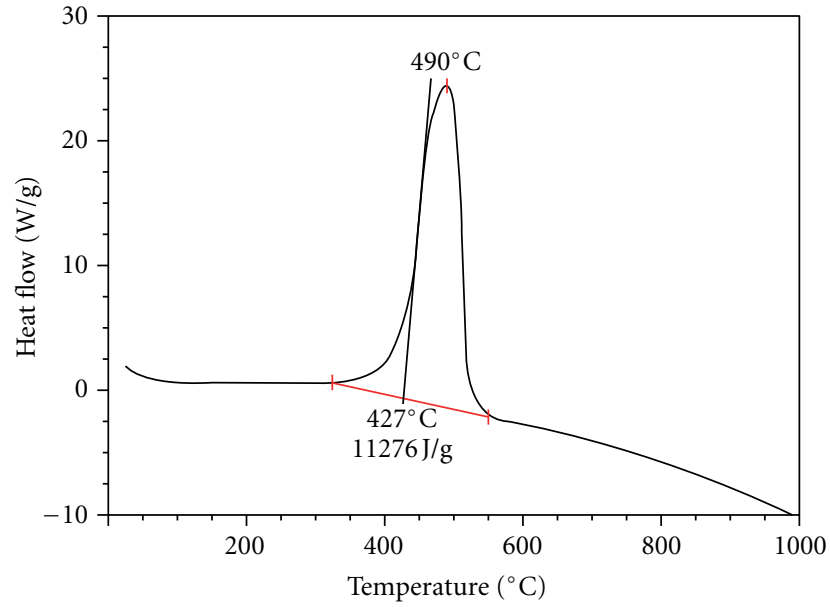

(b)

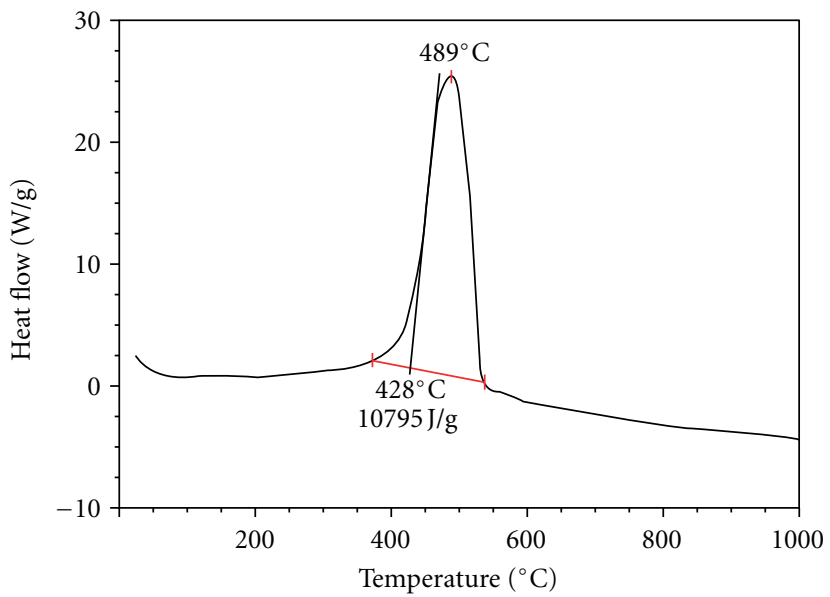

(c)

FIgURE 3: DSC curve for (a) S1, (b) S2, and (c) S3 dried powder.

where $\% m_{i}$ is the initial percent mass, $\% m_{t}$ is the percent mass at certain time $t$, and $\% m_{f}$ is the final percent mass as they are collected from the TG measurements. The prediction of the isothermal decomposition kinetics of the dried powder is shown in Figure 4. It can be seen that the rate of reaction for S1 is slower compared to S2 and S3. The reaction for S1 at 5\% conversion occurs within $t=19 \mathrm{~min}$. On the other hand, S2 and S3 showed a rapid reaction for the first decomposition stage where the reaction took place at $t=5 \mathrm{~min}$. The most kinetic reaction occurred at $\alpha=20-80$ for all samples. At this step, the second decomposition stage took place and the rate of reaction increased as the oxidation and combustion of chelate complex rapidly occured. This observation is in-line with the TG/DTG results as discussed earlier. It is believed that all the metal ions had chelate and coordinate to the oxygen and nitrogen donor atom in CA-EDTA complex. It has been recognized that alkali and alkaline-earth $\left(\mathrm{Ba}^{2+}\right)$ cations are effectively complexed by the carboxylic group, while transition metal cations $\left(\mathrm{Zr}^{4+}, \mathrm{Y}^{3+}\right)$ and rare earth cations $\left(\mathrm{Ce}^{3+}\right)$ are effectively complexed by the amine group. The metal ions may be distributed inhomogeneously when using single citric acid because its structure containing only three $-\mathrm{COOH}$ that need to bind metal ions, and at the same time reacted with polyethylene glycol to form polyester with a suitable viscosity. Single EDTA contains four - $\mathrm{COOH}$ and two amine groups that can bind to the metal ions. So, the combination of CA-EDTA gives sufficient site for these cations to coordinate to the chelating agents and retain complete complexation.

3.2. Infrared Spectra Analysis. Figure 5 presents the FTIR spectra of three gels. The broad bands $3177 \mathrm{~cm}^{-1}, 3414 \mathrm{~cm}^{-1}$, and $3450 \mathrm{~cm}^{-1}$ are attributed to $\mathrm{O}-\mathrm{H}$ stretching vibration of absorbed $\mathrm{H}_{2} \mathrm{O}$, carboxylic acid, and ethylene glycol. Peaks localized at $\sim 1622 \mathrm{~cm}^{-1}$ and $\sim 1342 \mathrm{~cm}^{-1}$ can be attributed to the residual organic groups. The bands at $\sim 1435 \mathrm{~cm}^{-1}$ can be assigned to the stretching vibration of symmetric and asymmetric carboxylate $(\mathrm{O}-\mathrm{C}-\mathrm{O})$. The $\mathrm{O}-\mathrm{C}-\mathrm{O}$ was formed from the coordination of the chelating agents and the metal cations. The bands at $750 \mathrm{~cm}^{-1}$ and below are assigned to metal-oxygen $(\mathrm{M}-\mathrm{O})$ stretching mode from the coordination 


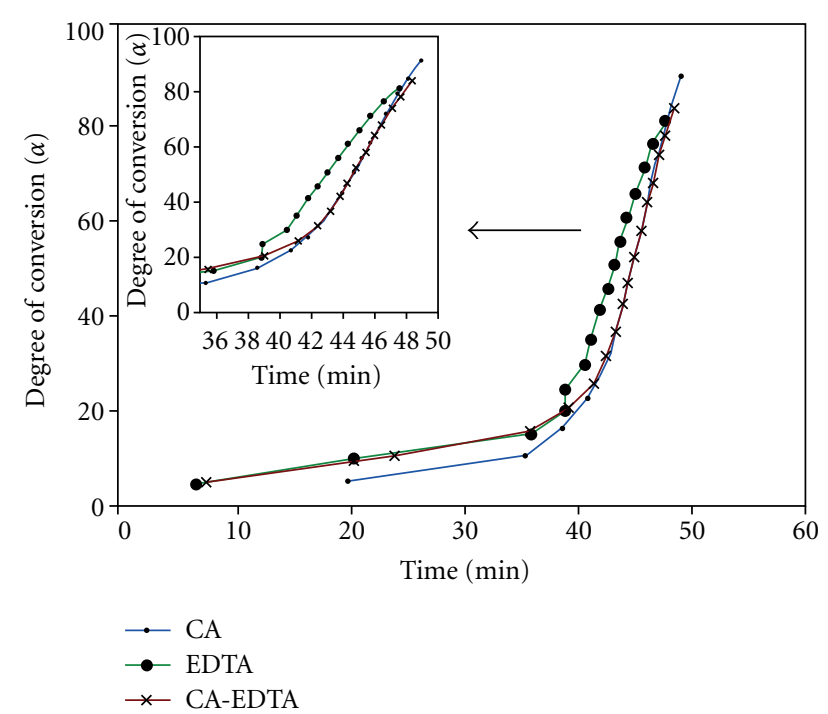

FIgURE 4: Degree of conversion versus time curve for the thermal decomposition of dried powder.

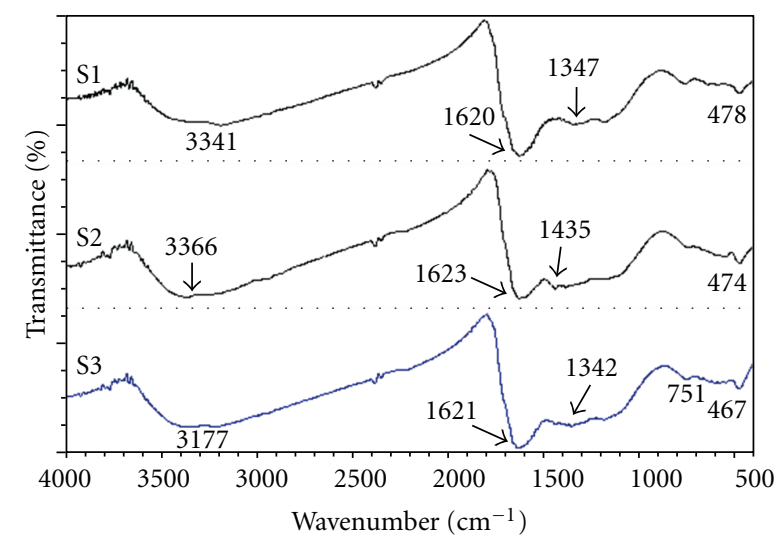

FIGURE 5: FTIR spectra of dried powder $\left(325^{\circ} \mathrm{C}\right)$ for S1, S2, and S3.

of chelating agents, and metallic ions proved that the chelation has occurred.

The evolution of FTIR spectra for S3 at different temperatures is illustrated in Figure 6. There are obviously changes of the peak at various calcination temperatures. When the gel is calcined at $550^{\circ} \mathrm{C}$ for $10 \mathrm{~h}$, the band at $1635 \mathrm{~cm}^{-1}$ is attributed to the carboxylate stretching metallic complex form from the carboxyl group and metallic ions. This peak is still observed for the powders even after calcined at $1100^{\circ} \mathrm{C}$ at $10 \mathrm{~h}$. This may refer to the strong chelating ability of the combination of citric acid-EDTA as chelating agents. Bands at $\sim 1437 \mathrm{~cm}^{-1}, \sim 1384 \mathrm{~cm}^{-1}$, and $858 \mathrm{~cm}^{-1}$ are attributed to the symmetric stretching vibration for carboxylate ions and nitrate. The broad peak present in the region $471 \mathrm{~cm}^{-1}$ refers to the evolution of the perovskite structure of the sample. It is clearly seen that the peak at $471 \mathrm{~cm}^{-1}$ becomes more stronger as the calcination temperature increases indicating that the formation of the perovskite structure may be enhanced.

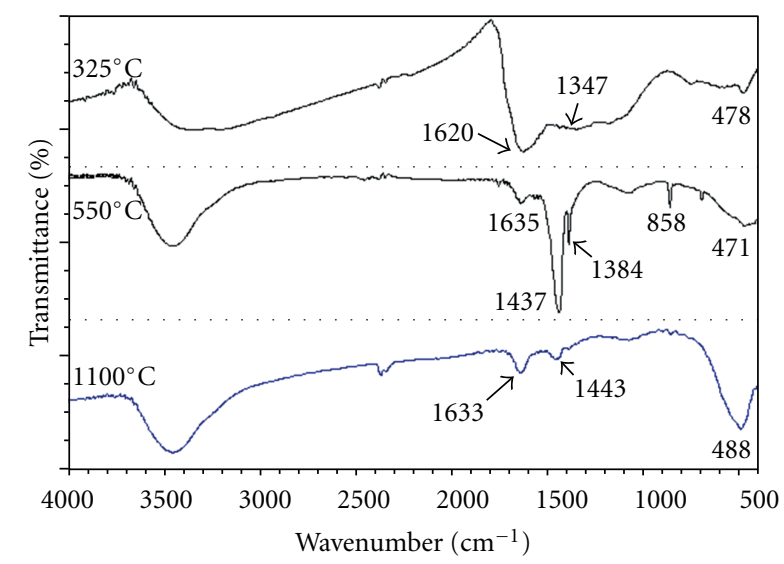

FIGURE 6: FTIR spectra for S3 at different calcination temperatures $\left(325^{\circ} \mathrm{C}, 550^{\circ} \mathrm{C}\right.$, and $\left.1100^{\circ} \mathrm{C}\right)$.

However we found that a low transmittance intensity of carbonate residue peaks at $\sim 1443 \mathrm{~cm}^{-1}$ is still remained in the spectra. Carbonates are influenced by the incomplete combustion of the carboxylic group that burn to $\mathrm{CO}_{2}$ and some of the $\mathrm{CO}_{2}$ molecules are adsorbed on the powders bind to $\mathrm{Ba}^{2+}$ and formed barium carbonates, $\mathrm{BaCO}_{3}$ compound [15]. The presence of $\mathrm{BaCO}_{3}$ impurities will lead to the loss of mechanical integrity and properties of the cerate-zironate powder because high calcination temperature $\left(\approx 1400^{\circ} \mathrm{C}\right)$ is needed to produce a pure single-phase of cerate-zirconate compound $[16,17]$. Therefore, a comparatively strong chelating agents like a combination of CA-EDTA is a better choice to produce cerate-zirconate powders with less impurities and at the same time can suppress the formation of $\mathrm{BaCO}_{3}$.

\section{Conclusion}

Cerate-zirconate powders were prepared by a modified solgel method using citric acid, EDTA, and a combination of CA-EDTA as a chelating agents. TGA results showed the thermal decomposition of $\mathrm{S} 3\left(750^{\circ} \mathrm{C}\right)$ is lower compared to $\mathrm{S} 2\left(770^{\circ} \mathrm{C}\right)$ and $\mathrm{S} 1\left(800^{\circ} \mathrm{C}\right)$. Heat released for $\mathrm{S} 1$ is higher due to the insufficiency of citric acid to chelate all metal ions. The thermal behaviour of BCZY powders was apparently influenced by the different types of the electron donating group from the chelating agents used. TGA and FTIR results revealed that the temperature $>1100^{\circ} \mathrm{C}$ is needed to decompose the remaining carbonate species. Further analysis on the formation of perovskite phase using X-ray diffraction (XRD) is still in progress and will be reported elsewhere.

\section{Acknowledgments}

The authors would like to thank the Ministry of Higher Education for the Grant 600-RMI/ST/FRGS 5/3/Fst (24/2010) and Universiti Teknologi MARA for the Grant 600-RMI/ST/DANA 5/3/Dst (61/2011). 


\section{References}

[1] Z. Zhong, "Stability and conductivity study of the $\mathrm{BaCe}_{0.9-x} \mathrm{Z}_{\mathrm{rx}} \mathrm{Y}_{0.1} \mathrm{O}_{2.95}$ systems," Solid State Ionics, vol. 178, no. 3-4, pp. 213-220, 2007.

[2] N. Osman, A. M. Jani, and I. A. Talib, "Synthesis of Yb-doped $\mathrm{Ba}(\mathrm{Ce}, \mathrm{Zr}) \mathrm{O}_{3}$ ceramic powders by sol-gel method," Ionics, vol. 12, no. 6, pp. 379-384, 2006.

[3] K. H. Ryu and S. M. Haile, "Chemical stability and proton conductivity of doped $\mathrm{BaCeO}_{3}-\mathrm{BaZrO}_{3}$ solid solutions," Solid State Ionics, vol. 125, no. 1, pp. 355-367, 1999.

[4] S. Liu, X. Tan, K. Li, and R. Hughes, "Synthesis of strontium cerates-based perovskite ceramics via water-soluble complex precursor routes," Ceramics International, vol. 28, no. 3, pp. 327-335, 2002.

[5] J. Cai, K. Laubernds, F. S. Galasso et al., "Preparation method and cation dopant effects on the particle size and properties of $\mathrm{BaCeO}_{3}$ perovskites," Journal of the American Ceramic Society, vol. 88, no. 10, pp. 2729-2735, 2005.

[6] P. Babilo, T. Uda, and S. M. Haile, "Processing of yttriumdoped barium zirconate for high proton conductivity," Journal of Materials Research, vol. 22, no. 5, pp. 1322-1330, 2007.

[7] D. Gao and R. Guo, "Yttrium-doped barium zirconate powders synthesized by the gel-casting method," Journal of the American Ceramic Society, vol. 93, no. 6, pp. 1572-1575, 2010.

[8] N. Osman, I. A. Talib, and H. A. Hamid, "Preparation and characterization of $\mathrm{Yb}$-doped barium cerate prepared by Pechini method," Solid State Science and Technology Letters, vol. 15, pp. 62-67, 2008.

[9] M. Motta, C. V. Deimling, M. J. Saeki, and P. N. LisboaFilho, "Chelating agent effects in the synthesis of mesoscopicsize superconducting particles," Journal of Sol-Gel Science and Technology, vol. 46, no. 2, pp. 201-207, 2008.

[10] Y. Li, J. Zhao, and B. Wang, "Low temperature preparation of nanocrystalline $\mathrm{Sr}_{0.5} \mathrm{Ba}_{0.5} \mathrm{Nb}_{2} \mathrm{O}_{6}$ powders using an aqueous organic gel route," Materials Research Bulletin, vol. 39, no. 3, pp. 365-374, 2004.

[11] Y. Tao, J. Shao, J. Wang, and W. G. Wang, "Synthesis and properties of $\mathrm{La}_{0.6} \mathrm{Sr}_{0.4} \mathrm{CoO}_{3-\delta}$ nanopowder," Journal of Power Sources, vol. 185, no. 2, pp. 609-614, 2008.

[12] J. Shao, Y. Tao, J. Wang, C. Xu, and W. G. Wang, "Investigation of precursors in the preparation of nanostructured $\mathrm{La}_{0.6} \mathrm{Sr}_{0.4} \mathrm{Co}_{0.2} \mathrm{Fe}_{0.8} \mathrm{O}_{3-\alpha}$ via a modified combined complexing method," Journal of Alloys and Compounds, vol. 484, no. 1-2, pp. 263-267, 2009.

[13] V. Agarwal and M. Liu, "Preparation of barium cerate-based thin films using a modified Pechini process," Journal of Materials Science, vol. 32, no. 3, pp. 619-625, 1997.

[14] S. Roy, W. Sigmund, and F. Aldinger, "Nanostructured yttria powders via gel combustion," Journal of Materials Research, vol. 14, no. 4, pp. 1524-1531, 1999.

[15] Y. Sang, H. Liu, Y. Lv et al., "Yttrium aluminum garnet nanoparticles synthesized by nitrate decomposition and their low temperature densification behavior," Journal of Alloys and Compounds, vol. 490, no. 1-2, pp. 459-462, 2010.

[16] H. W. Wang, "Inhibition of the formation of barium carbonate by fast heating in the synthesis of $\mathrm{BaTiO}_{3}$ powders via an EDTA gel method," Materials Chemistry and Physics, vol. 74, no. 1, pp. $1-4,2002$.
[17] C. S. Tu, C. C. Huang, S. C. Lee, R. R. Chien, V. H. Schmid, and C. L. Tsai, "Effect of lithium fluoride on thermal stability of proton-conducting $\mathrm{Ba}\left(\mathrm{Zr}_{0.8-x} \mathrm{Ce}_{\mathrm{x}} \mathrm{Y}_{0.2}\right) \mathrm{O}_{2.9}$ ceramics," Solid State Ionics, vol. 181, no. 37-38, pp. 1654-1658, 2010. 

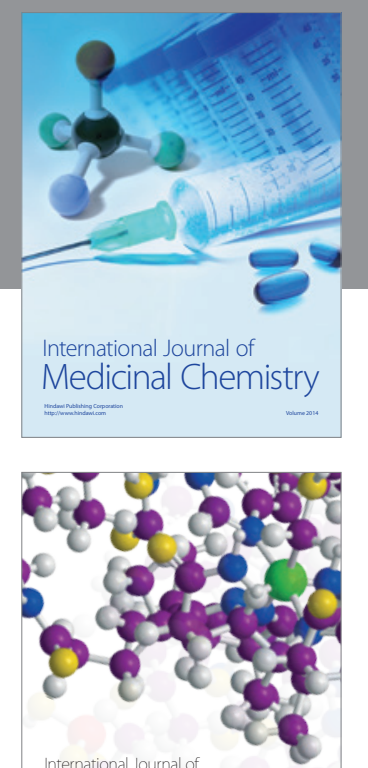

\section{Carbohydrate} Chemistry

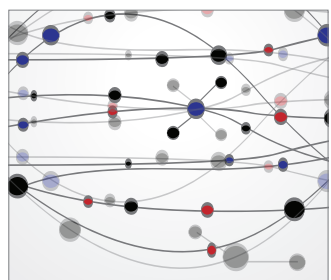

The Scientific World Journal
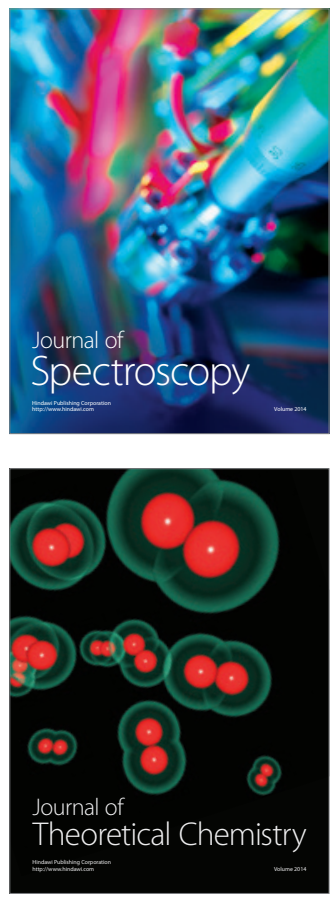
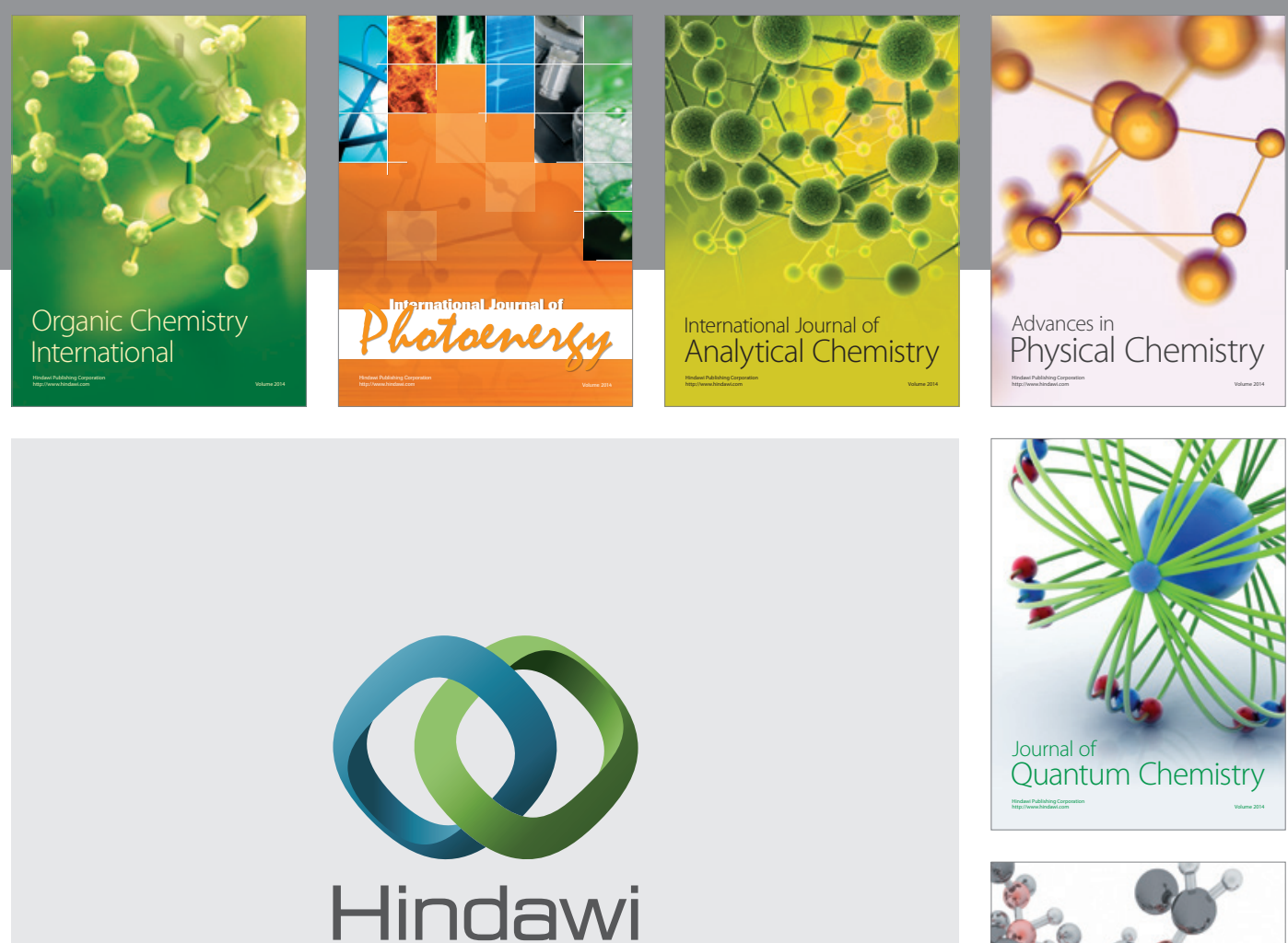

Submit your manuscripts at

http://www.hindawi.com

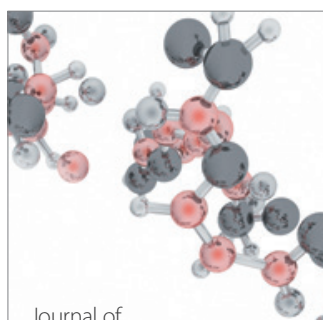

Analytical Methods

in Chemistry

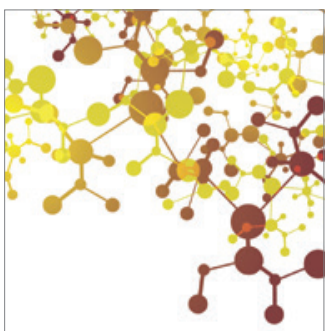

Journal of

Applied Chemistry

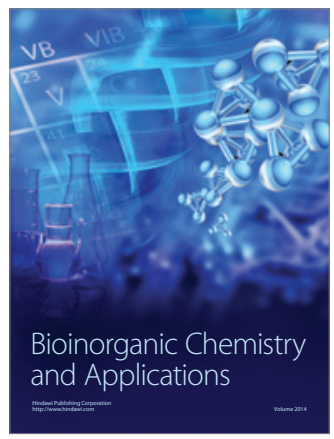

Inorganic Chemistry
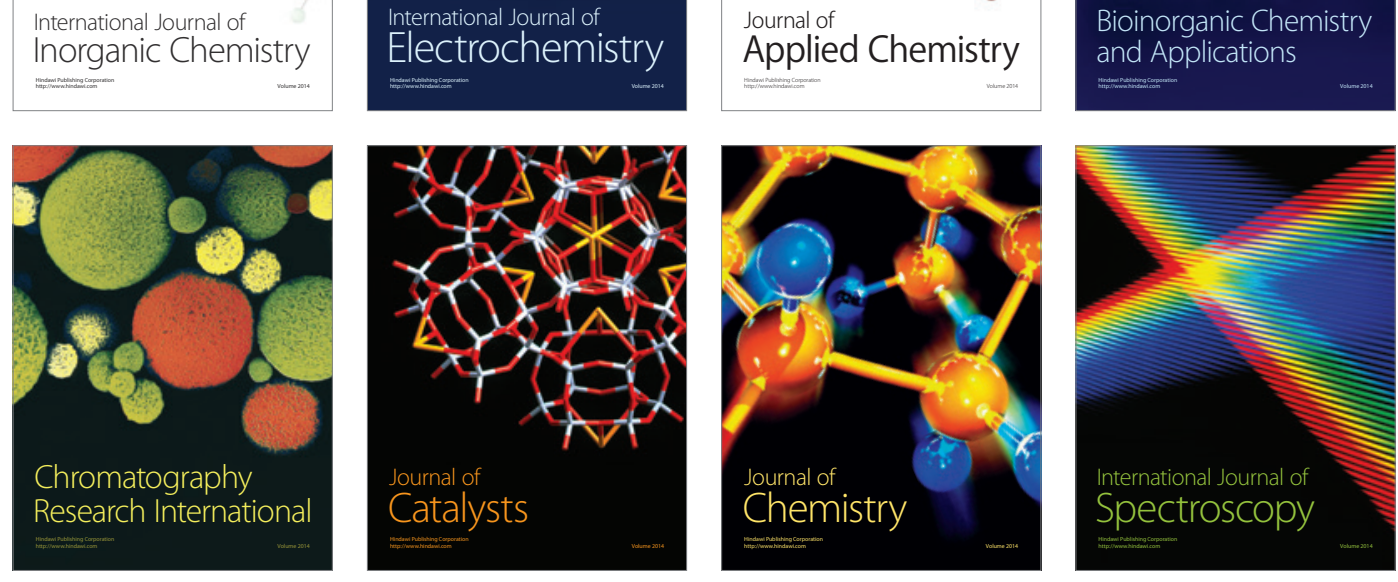